\title{
Biological basis for the surgical treatment of depression
}

\author{
Aviva Abosch, M.D., Ph.D., ${ }^{1}$ And G. Rees Cosgrove, M.D., F.R.C.S.C. ${ }^{2}$ \\ ${ }^{1}$ Department of Neurosurgery, University of Minnesota Medical School, Minneapolis, Minnesota; and \\ ${ }^{2}$ Department of Neurosurgery, Lahey Clinic Medical Center, Burlington, Massachusetts
}

\begin{abstract}
An estimated $20 \%$ of patients with major depression are refractory to existing therapies. The purpose of this review is to provide a theoretical and neuroscientific framework in which to interpret new work in the field of surgical treatment for depression. This review focuses on existing clinical and imaging data, current disease models, and results of recent case reports and patient series that together may inform the construction of appropriate clinical trials for the surgical treatment of refractory depression. (DOI: $10.3171 /$ FOC/2008/25/7/E2)
\end{abstract}

KEY WorDS • deep brain stimulation • depression • functional imaging

\section{The Importance of a Biological/Mechanistic Approach to Surgery for Depression}

The successful application of DBS to the treatment of movement disorders ${ }^{24,26,68,111,127}$ has renewed interest in the surgical treatment of depression. Although the field of psychosurgery has its roots in anecdotal experience as opposed to hypothesis-driven experimentation assessed with validated outcome measures, a new era is fortunately emerging. Advances in the field of neuroimaging have allowed the use of human participants for testing hypotheses about the mechanisms that underlie these disorders. In addition to higher expectations and greater scrutiny placed on investigations in this arena, the advent of DBS technology has provided investigators with a tool that is nondestructive, modifiable, capable of being turned on or off, and more focal in its effects than psychotropic medications.

Depression is now viewed as a neural "network problem," as opposed to dysfunction in one particular neural structure or neurotransmitter. ${ }^{75}$ This network (or networks) can be regarded as a collection of interconnected gray matter nodes and white matter pathways. There are as yet no careful clinical trials published that would enable a rational decision to be made regarding the optimal DBS target within this network for the treatment of depression. The purpose of this review is to highlight the existing clinical and

\footnotetext{
Abbreviations used in this paper: $\mathrm{ACC}=$ anterior cingulate cortex; $\mathrm{CBT}=$ cognitive behavioral therapy; CGPS = Clinical Global Psychiatric-Social Status; DBS = deep brain stimulation; DTI = diffusion tensor imaging; ECT = electroconvulsive therapy; FDG $=$ fluorine-18-labeled fluorodeoxyglucose; HRSD = Hamilton Rating Scale for Depression; MADRS = Montgomery-Åsberg Depression Rating Scale; OCD = obsessive-compulsive disorder; OFC = orbitofrontal cortex; PD = Parkinson disease; SSRI = serotoninselective reuptake inhibitor.
}

imaging data, the current disease models, and the results of recent case reports and patient series that together may inform the construction of appropriate clinical trials.

\section{The Clinical Picture of Depression}

Depression is estimated to affect 121 million people worldwide, ranks among the leading causes of disability worldwide (http://www.who.int/mental_health/management/depression/definition/en), and is increasing annually in terms of its contribution to the global burden of disease. An estimated 850,000 patients annually commit suicide. The mainstay of therapy for severe depression has been a combination of pharmacotherapy and CBT, with ECT reserved for those patients who do not respond to medication and CBT. The medications used to treat depression result in the manipulation of neurotransmitter levels throughout the brain, often leading to unacceptable side effects and difficulty with patient compliance. ${ }^{60}$ Although the majority of patients with major depression respond to medication and/or psychotherapy, $20 \%$ of patients are refractory to existing therapies. For these treatment-refractory patients, novel therapies are being sought. These therapies include vagus nerve stimulation, repetitive transcranial magnetic stimulation, and DBS. This review will focus on the ongoing work in DBS for depression, and the reader is referred to other sources for reviews on vagus nerve stimulation $^{87}$ and repetitive transcranial magnetic stimulation ${ }^{29}$ for the treatment of major depression.

Depression is now increasingly regarded as a "systemslevel" disorder, as opposed to a disorder that results from a single neuroanatomical structure or neurotransmitter abnormality ${ }^{75}$ The mechanism or mechanisms that drive this system dysfunction are as yet not well characterized, but are likely to involve developmental insults superimposed 
on genetic susceptibility and affective temperament. ${ }^{77} \mathrm{~A}$ wealth of functional neuroimaging data has contributed to this framework for conceptualizing depression and led to hypothesis-driven approaches to the treatment of refractory depression. In addition to the possibility of elucidating the underlying mechanism of depression, functional neuroimaging holds the promise of identifying biomarkers that could be used to guide therapeutic interventions in different subpopulations of depressed patients.

\section{Converging Lines of Evidence}

\section{Historical Human Ablative Limbic System Surgery Data}

As noted above, the history of psychosurgery is one of appropriate public and governmental concern. Studies purporting to demonstrate the efficacy of the various psychosurgery techniques are mostly retrospective and open (noncontrolled) in nature, and lacking in appropriate control arms for comparison. ${ }^{72}$ Despite these caveats, there are ample data to support the efficacy and reasonable sideeffect profile of the more limited ablative limbic system surgeries for patients who have exhausted other treatment options. Psychiatric diagnosis has improved considerably since the early days of psychosurgery, with the standardization afforded by the Diagnostic and Statistical Manual of Mental Disorders and the adoption of validated and objective rating scales for tracking improvements in psychiatric symptoms following therapy. ${ }^{85}$ Although interest has shifted substantially away from lesion surgery and toward neuromodulation procedures - such as the implantation of DBS devices - ablative limbic system surgery is still performed. ${ }^{74,118}$ The ablative procedures currently in use include anterior limb capsulotomy, anterior cingulotomy, ${ }^{118}$ subcaudate tractotomy, and rarely, the combination of cingulotomy and subcaudate tractotomy, known as limbic leukotomy ${ }^{130}$ Although varying methodologies for patient selection and postoperative assessment exist in the reported series, it is interesting to note that the standard lesioning approaches - anterior capsulotomy, subcaudate tractotomy, and cingulotomy - all result in comparable clinical effica$\mathrm{cy},{ }^{22}$ although the white matter tracts severed in each procedure are different. These results are briefly summarized below.

Anterior Capsulotomy. Anterior capsulotomy involves the generation of a lesion in frontothalamic fibers that pass through the anterior limb of the internal capsule, ventral to the putamen and the head of the caudate nucleus, and immediately dorsal to the nucleus accumbens..$^{74}$ Anterior capsulotomy has been associated with a $70 \%$ success rate in patients with OCD. ${ }^{14}$ Although this procedure continues to be used for the treatment of major depression, ${ }^{105}$ the primary indication for anterior capsulotomy is now OCD. Interestingly, adverse effects of capsulotomy include depression, which is reported to resolve over time. ${ }^{83}$

Cingulotomy. Cingulotomy, initially performed as a stereotactic procedure by Foltz and White ${ }^{38}$ in 1962, involves the generation of bilateral thermocoagulation or radiosurgery lesions in the ACC as well as the fibers of the cingulum. ${ }^{23,28}$ Lesions in this region are believed to result in thalamofrontal pathway disruption, pathways that are involved in the mediation of anxiety and depression. Also arising in the anterior cingulate region are extensive projections to amygdala, periaqueductal gray, and autonomic brainstem motor nuclei, connections that are involved in the mediation of emotion and autonomic responses. ${ }^{27}$ Ballantine and colleagues ${ }^{6}$ reported significant improvement in $64 \%$ of patients with major depression treated using cingulotomies. Patients were assessed using the CGPS scale, which measures functional outcome following therapy. A CGPS scale score of 3,4 , or 5 is consistent with response to treatment. More recently, using the same outcome criteria, Spangler and associates ${ }^{115}$ reported a significant improvement (CGPS scale score of 3,4 , or 5) in $60 \%$ of patients undergoing cingulotomies for major depression.

Subcaudate Tractotomy. Subcaudate tractotomy, which involves the generation of bilateral lesions in the substantia innominata of the basal forebrain immediately ventral to the head of the caudate, ${ }^{63}$ has been used for many decades to treat refractory affective and anxiety disorders, including depression and OCD. ${ }^{74}$ In a study published in 1975 by Göktepe and colleagues, ${ }^{46} 68 \%$ of patients with depression had "recovered" or were "much improved" after subcaudate tractotomy. The Wakefield Depression Inventory 114 was used to rate patients' symptoms at the time of review (2.5-4.5 years postoperatively), but no comparison preoperative data were provided. Other reports cite outcome after subcaudate tractotomy for depression as "good" in 34-56\% of patients..$^{54,120}$ More recently, Poynton et al. ${ }^{101}$ prospectively studied a cohort of 23 patients (70\% with major depressive disorder and $30 \%$ with bipolar disorder) undergoing subcaudate tractotomy. Testing at 6 months following surgery disclosed significant improvements in depression, with a $54 \%$ improvement on the HRSD. ${ }^{50}$

Limbic Leucotomy. Limbic leukotomy combines lesion formation in the ACC with subcaudate tractotomy, and was introduced as a means of combining the therapeutic efficacy of the individual procedures. ${ }^{61}$ Limbic leukotomy has been used for the treatment of refractory major depression and OCD. Montoya and associates ${ }^{85}$ reported their results using limbic leukotomy for the treatment of 6 patients with major depressive disorder who underwent operations between 1993 and 1999. One patient committed suicide postoperatively. Of the remaining patients, $3(50 \%)$ demonstrated significant improvement on the CGPS rating scale, consistent with treatment response.

Existing data thus suggest that the lesion procedures described above-regardless of whether the anterior capsule, cingulum, or subcaudate white matter is severedoffer benefit to a large proportion of patients (35-70\%) with intractable depression. ${ }^{48}$ This finding provides support for the idea that a network, rather than a single neural target, underlies the mechanism as well as the successful remediation of major depression.

\section{Evidence From Central Nervous System Injury Literature}

There is mounting evidence from the clinical literature that discrete lesions - whether from stroke, tumor, or toxic exposure - can induce neuropsychiatric disorders such as depression, obsessive-compulsive behavior, and Tourettism. The evidence for an association between the anatomical location of a lesion and the onset of depression is less clear. 
Depression following cerebral infarction is common, ${ }^{129}$ with an incidence rate of $14-47 \%$ depending on study methodology. ${ }^{56}$ Surprisingly, though, the level of debilitation resulting from the infarct does not necessarily correlate with likelihood of depression. ${ }^{29}$ This observation suggests that depression might be a direct biological consequence of the infarct rather than a reactive depression. ${ }^{129}$ Some investigators believe that infarct location in the brain is correlated with the likelihood of poststroke depression, ${ }^{106,116}$ although this is controversial (see below). Robinson et al. ${ }^{106}$ reported that patients with anterior infarcts in the left frontal cortex or within the left basal ganglia had the highest frequency of depression, with the severity of depression correlating with how far anteriorly the infarct was located. Starkstein and colleagues ${ }^{116,117}$ reported a greater incidence of poststroke depression following lesions of the left frontal cortex or left basal ganglia, and more recently, BarkerCollo ${ }^{8}$ noted that depression was more likely to occur in patients sustaining left versus right hemisphere strokes. These observations support the hypothesis that damage in specific locations results in disruption of the neural circuits involved in mood regulation. ${ }^{10}$

In contrast, Fure et al..$^{44}$ published a study of 178 patients with strokes, demonstrating no relationship between infarct location and likelihood of poststroke depression. Also, a meta-analysis of reports published between 1966 and 1999 on the association between poststroke depression and stroke location by Carson and colleagues ${ }^{21}$ found no support for an association between the risk of depression and location of infarct.

\section{Mood and Behavioral Effects of DBS for Movement Disorders}

Deep brain stimulation for the treatment of movement disorders has been reported to result in a variety of mood changes. It is important to remember that levodopa, by itself, can have psychotropic effects ${ }^{43}$ and that most patients with PD who undergo surgery for the implantation of DBS electrodes are also taking levodopa. Furthermore, subthalamic nucleus DBS and levodopa have synergistic effects, often requiring titration of medication dose and/or adjustment stimulation parameters immediately after surgery. ${ }^{86}$ This manipulation of drug dose and stimulation parameters can confound efforts to determine which effects can be attributed to medication, stimulation, or both. Many patients also take dopamine agonists such as pramipexole, which has been implicated in compulsive gambling in patients with PD. Nonetheless, changes attributed to DBS have included depression, ${ }^{66}$ aggression, ${ }^{11}$ hypomania, ${ }^{42,73}$ mania, ${ }^{122}$ apathy, ${ }^{31,110}$ and inappropriate laughter. ${ }^{65}$ In a prospective study of 20 patients with PD treated with subthalamic nucleus DBS, Houeto and colleagues ${ }^{55}$ reported an improvement in depression severity of $21 \%$ at 6 months and $33 \%$ at 24 months. In contrast, a recent report by Berney and colleagues ${ }^{12}$ found that acute DBS in a small series of 15 patients did not result in clinically significant mood alterations. Additionally, globus pallidus interna DBS for the treatment of generalized dystonia in $22 \mathrm{pa}-$ tients resulted in no significant behavioral or mood changes. ${ }^{97}$ However, Kosel and colleagues ${ }^{64}$ described a patient with neuroleptic-induced tardive dyskinesia and comorbid major depression who underwent DBS. For the treatment of her tardive dyskinesia, the patient underwent implantation of bilateral DBS electrodes within the globus pallidus internus, at a location $2 \mathrm{~mm}$ medial to the target generally used for PD. Following 18 months of nonblinded stimulation, the patient's dystonic symptoms had improved by $35 \%$, with improvements occurring primarily in the limbs and only minimal improvements in her disabling oromandibular dyskinesia. Interestingly, her depression had improved significantly, decreasing by $50 \%$ on the HRSD. ${ }^{50}$

\section{Physiological Models of Basal Ganglia Function and Disease}

In 1983 Penney and Young ${ }^{96}$ presented a model that highlighted the importance of the cortico-striato-pallidothalamocortical feedback circuit as the major extrapyramidal influence on the motor system in man. A revolutionary approach to thinking about basal ganglia physiology was published in 1986 when Alexander et al. ${ }^{2}$ proposed the parallel pathway hypothesis. Building on rapidly accumulating evidence, Alexander and colleagues proposed 5 parallel, segregated cortico-striato-thalamo-cortical circuits (Fig. 1), with each circuit (motor, oculomotor, dorsolateral prefrontal, lateral orbitofrontal, and anterior cingulate) engaging specific regions of the cerebral cortex, striatum, pallidum, substantia nigra, and thalamus. Hypokinetic movement disorders were proposed to result from overactivity of the globus pallidus interna, and hyperkinetic disorders from decreased activity in the globus pallidus internus. ${ }^{124}$ The model put forth by Alexander and colleagues was subsequently modified to include connections between the cortex and thalamus through 4 parallel loops, including motor, spatial, visual, and affective loops ${ }^{82} \mathrm{~A}$ recent metaanalysis of PET and functional MR imaging research ${ }^{100}$ indicates that the functional connectivity between the cortex and the different striatal nuclei are broadly consistent with the predictions of the parallel pathway model.

At present, on the basis of anatomical and physiological studies and the success of surgical interventions, both movement disorders and neuropsychiatric disorders (such as depression, OCD, and Tourette syndrome) are now viewed as circuit disorders resulting from pathological disturbances in neuronal activity within specific cortico-subcortical loops. ${ }^{25,76}$ A review of the relevant anatomical regions and pathways follows below.

\section{Anatomy of Depression}

Serving as the link between the frontal lobe and thalamus, the anterior limb of the internal capsule contains the prefrontal corticopontine tract and the anterior thalamic radiation. The anterior thalamic radiation interconnects the prefrontal cortex and cingulate gyrus with the anterior and dorsomedial thalamic nuclei..$^{95}$ Although the precise function of the anterior nuclear group in humans remains unknown, both the anterior nuclear group and dorsomedial nucleus are densely connected with cortical and subcortical limbic areas..$^{95}$

The nucleus accumbens is located in the ventral-most aspect of the medial striatum ${ }^{49}$ and is heavily connected to limbic areas of the brain..$^{53}$ The nucleus accumbens receives projections from a large number of brain regions, including 

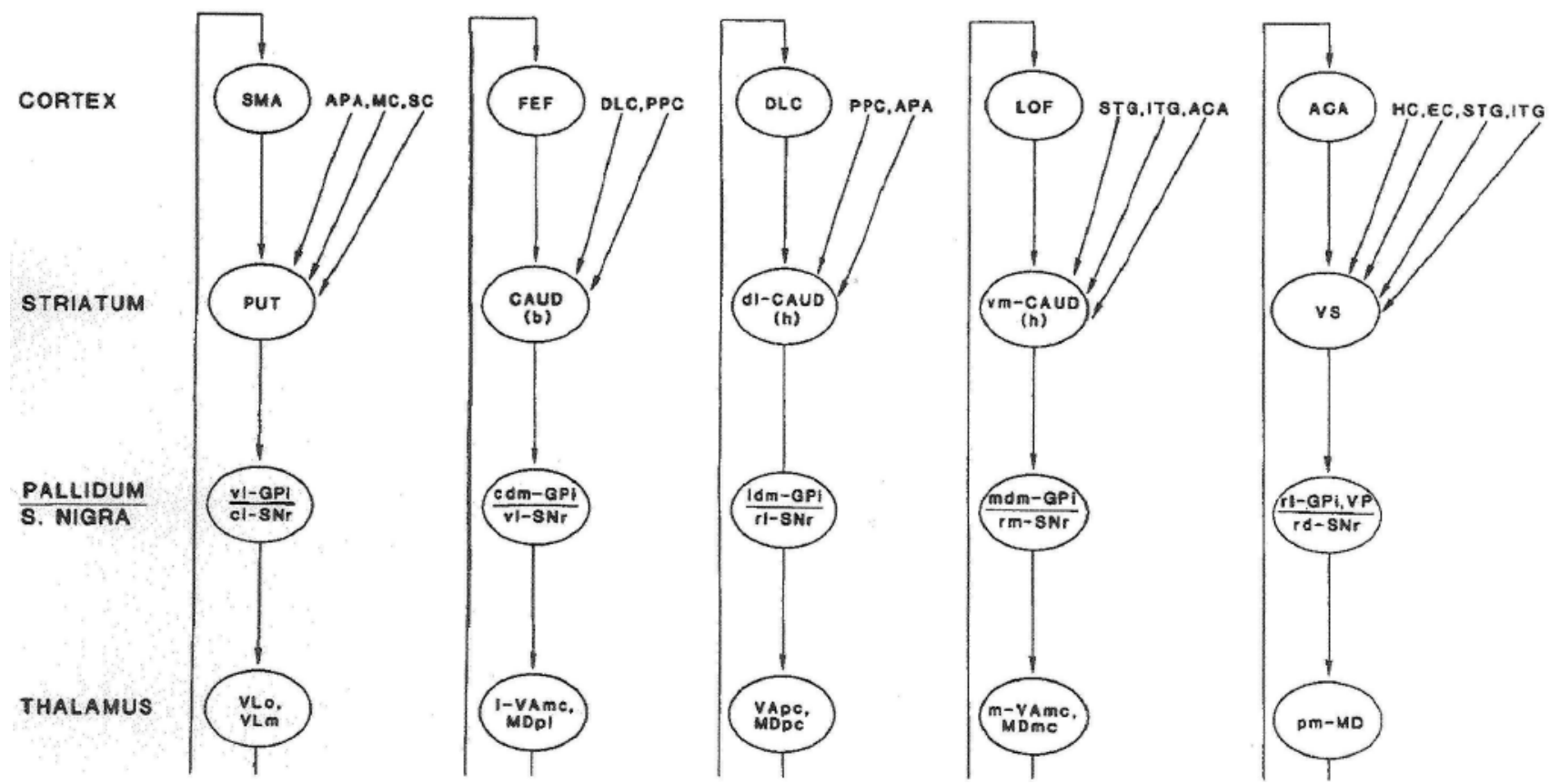

FIG. 1. Diagram of the parallel circuits of basal ganglia processing. ACA = anterior cingulate area; $A P A=$ arcuate premotor area; $(\mathrm{b})=$ body; CAUD = caudate; $\mathrm{cdm}=$ caudal dorsomedial; $\mathrm{cl}=$ caudolateral; $\mathrm{dl}=$ dorsolateral; $\mathrm{DLC}=\mathrm{dor}-$ solateral prefrontal cortex; $\mathrm{EC}=$ entorhinal cortex; $\mathrm{FEF}=$ frontal eye fields; GPI = internal segment of globus pallidus; (h) = head; HC = hippocampal cortex; ITG = inferior temporal gyrus; 1 = lateral; ldm = lateral dorsomedial; LOF = lateral orbitofrontal cortex; $\mathrm{m}=$ medial; $\mathrm{MC}=$ motor cortex; $\mathrm{mdm}=$ medial dorsomedial; $\mathrm{MDmc}=$ medialis dorsalis pars magnocellularis; $\mathrm{MDpc}=$ medialis dorsalis pars parvocellularis; $\mathrm{MDpl}=$ medialis dorsalis pars paralamellaris; $\mathrm{pm}=\mathrm{pos}-$ teromedial; $\mathrm{PPC}=$ posterior parietal cortex; PUT = putamen; $\mathrm{rd}=$ rostrodorsal; $\mathrm{rl}=$ rostrolateral; $\mathrm{rm}=$ rostromedial; $\mathrm{S}$. $=$ substantia; $\mathrm{SC}=$ somatosensory cortex $; \mathrm{SMA}=$ supplementary motor area; $\mathrm{SNr}=$ substantia nigra pars reticulata; $\mathrm{STG}$ $=$ superior temporal gyrus; VAmc $=$ ventralis anterior pars magnocellularis; VApc $=$ ventralis anterior pars parvocellularis; $\mathrm{vl}=$ ventrolateral; VLm $=$ ventralis lateralis pars medialis; VLo $=$ ventralis lateralis pars oralis; $\mathrm{vm}=$ ventromedial; VP = ventral pallidum; VS = ventral striatum. From Alexander GE, Delong MR, Strick PL: Parallel organization of functionally segregated circuits linking basal ganglia and cortex. Ann Rev Neurosci 9:357-381, 1986. Material in the public domain.

dopaminergic projections from the midbrain and projections from the OFC, medial prefrontal cortex, ${ }^{49}$ and amygdala, ${ }^{84}$ all regions involved in the processing of emotion. The nucleus accumbens also receives projections from motor control centers such as the globus pallidus and from regions involved in memory such as the hippocampus. ${ }^{40}$ The nucleus accumbens sends projections to midbrain dopaminergic neurons within the ventral tegmental area and substantia nigra pars compacta, as well as the medial prefrontal cortex, ventral pallidum, lateral hypothalamus, amygdala ${ }^{89}$ and subgenual cingulate. Based on the distribution of various neuropeptides, the nucleus accumbens is divided into an outer shell and a central core that surrounds the anterior commissure. ${ }^{18,81}$ The core projects primarily to motor-related regions of the basal ganglia, and the shell projects primarily to limbic structures.$^{53}$ The reward effect of cocaine has been associated with the release of dopamine in the nucleus accumbens. ${ }^{99}$

Situated on the medial surface of the frontal lobes, the ACC is composed of subdivisions that play critical roles in emotional processing, cognition, and motor function. ${ }^{19}$ The $\mathrm{ACC}$ has direct limbic and paralimbic connections and includes Brodmann areas 24, 32, and $25 .{ }^{49}$ In subhuman primates, Brodmann area 25 (subgenual cingulate), which underlies the genu of the corpus callosum (along with the caudal aspects of Brodmann areas 32 and 24), has projections to the medial caudate nucleus, amygdala, insula hypothalamus, ${ }^{92}$ midline and mediodorsal thalamic nuclei, and the periaqueductal gray, as well as widespread projections to subcortical structures that, in turn, project to widespread cortical areas,${ }^{39}$ including the OFC, medial prefrontal cortex, and cingulate cortex. These projections suggest a role for the subgenual cingulate in the control of visceromotor function. The interconnections of the subgenual cingulate with the OFC, medial prefrontal cortex, and cingulate cortex suggest a role for the subgenual cingulate in circadian regulation disturbances (sleep, libido, and appetite) and in the behavioral disturbances of depression (motivation, reward, learning, and memory). Two other regions of interest in the prefrontal cortex believed to function in the mediation of depression are the dorsolateral prefrontal cortex and the OFC, both of which are believed to be involved in reward response, cognitive flexibility, and executive functioning, respectively. ${ }^{107}$ 


\section{Functional Imaging in Depression}

Major depression is characterized by affective, cognitive, motor, and neuroendocrinological manifestations. Imaging research aimed at elucidating the mechanism or mechanisms underlying major depression has focused on the limbic component of the parallel cortico-striato-thalamocortical circuitry described above, in addition to the role of the hippocampus, amygdala, ACC, and hypothalamicpituitary axis. The involvement of these various structures could help to explain the heterogeneity of the symptoms manifested. ${ }^{104}$

Rauch ${ }^{104}$ segregates the implicated anatomical structures into a "dorsal compartment" (composed of the anterior, lateral, and dorsal prefrontal cortex; dorsal ACC; and premotor and parietal cortex) and a "ventral compartment" (composed of the subgenual cingulate, anterior insular cortex, and $\mathrm{OFC}$ ). Interestingly, major depressive disorder can be characterized, in general terms, by hyperactivity in the ventral compartment and hypoactivity in the dorsal compartment, as described below.

\section{Structural MR Imaging}

Morphometric MR imaging studies of major depressive disorder have variously demonstrated smaller volumes within structures of the limbic-cortical-striatal-pallidalthalamic network. Conflicting results are likely a consequence of the methodological and clinical heterogeneity across studies (see Sheline ${ }^{112}$ and Campbell and MacQueen ${ }^{20}$ for detailed reviews). For instance, studies have found reduced volume in bilateral anterior cingulate gray matter, ${ }^{7,15,35}$ but no volume differences have been demonstrated in depressed patients who are in remission or in patients with mild depression. ${ }^{16}$ Reduced volumes have also been noted in the subgenual cingulate, ${ }^{35,93}$ in the hippocampus, ${ }^{88,125}$ and in the striatum of patients with major depressive disorder, but again, other studies have failed to support these findings. ${ }^{69,108}$ Interestingly, postmortem analyses of patients who have died with depression have documented decreased volume in the hippocampus, ${ }^{119}$ striatum, ${ }^{9}$ and OFC. ${ }^{103}$ Methodological issues related to postmortem tissue processing and significant confounds associated with premortem medication history and symptoms make such studies difficult to interpret.

\section{Positron Emission Tomography}

The use of PET to measure resting-state glucose metabolism - a surrogate for neuronal activity — in depressed patients has most commonly revealed abnormalities in frontal and cingulate regions. Abnormalities have also been noted in limbic and subcortical structures, but these findings have been more variable. Differences among disorder subtypesfor instance, bipolar versus unipolar depression - and the heterogeneity of symptoms and variable presence of psychiatric comorbidities (such as anxiety), combined with technical differences between studies, presumably account for the variability in imaging findings (see Videbech ${ }^{128}$ for review). A sampling of PET studies highlighting abnormalities in these various structures is detailed below.

Decreased lateral prefrontal metabolism and increased metabolism in the medial prefrontal and subgenual cingulate regions have been noted in patients with depres- sion..$^{34,62,77}$ The severity of depression has been shown to correlate with the degree of hypermetabolism in the subgenual cingulate region. ${ }^{94}$ Moreover, the increased subgenual cingulate metabolism normalizes in patients with major depressive disorder who respond to treatment. ${ }^{62,77,79}$ Also, induced sadness in nondepressed control participants has been demonstrated to result in increased cerebral perfusion in the subgenual cingulate region (Brodmann area 25). ${ }^{71}$ Finally, Dougherty and colleagues ${ }^{30}$ performed preoperative resting-state FDG-PET imaging on 13 patients who then underwent an anterior cingulotomy for the treatment of major depressive disorder. The authors found that the degree of preoperative hypermetabolism noted in the left subgenual prefrontal cortex and in the left thalamus correlated with a greater percentage of improvement on the Beck Depression Inventory at 12 months following surgery. Together, these findings support the role of the subgenual cingulate in the modulation of depression and led to the trial of subgenual cingulate DBS for depression ${ }^{80}$ described later in this review.

Various investigators have noted increased resting-state activity within the ACC in imaging studies of patients with major depression. . $^{17,78,98}$ The increased ACC activity has been noted to normalize with treatment response. Mayberg et al. $^{78}$ found that metabolic activity on PET in the rostral anterior cingulate (Brodmann area 24a/b) could differentiate eventual drug treatment responders from nonresponders, showing that responders were hypermetabolic and nonresponders were hypometabolic compared with healthy controls. Hyperactivity in the resting state has also been noted in the OFC of patients with major depression during depressive episodes. ${ }^{33,36}$

\section{Diffusion Tensor Imaging}

Diffusion tensor imaging is used as a noninvasive means of investigating connectivity as well as the microstructure of white matter by measuring the diffusion of water molecules. Diffusion tensor imaging is subject to a number of limitations; for example, DTI cannot be used to determine the direction of pathways (retrograde vs anterograde) or to determine whether connections are direct or indirect..$^{59}$ Furthermore, DTI is better at detecting large fiber bundles without complex crossing patterns. Even with these limitations, DTI studies in elderly depressed patients have demonstrated white matter abnormalities in the frontal and temporal lobes..$^{90,121}$ In a large study comparing 106 depressed elderly patients and 84 age-matched healthy controls, depression was associated with a significantly lower fractional anisotropy in white matter lateral to the right ACC, bilateral superior frontal gyri, and left middle frontal gyrus, supporting the hypothesis of altered connectivity in brain regions implicated in depression. ${ }^{5}$ A recent DTI analysis of treatment-naïve young women (mean age 28.1 years, range 20-41 years) with major depression compared with healthy controls found significantly lower fractional anisotropy in the white matter of the superior and middle frontal gyri, regions traversed by fibers of the dorsolateral prefrontal circuit, suggesting that prefrontal white matter abnormalities are present early in the course of major depressive disorder. ${ }^{70}$

\section{Functional MR Imaging}

Functional MR imaging uses blood oxygen level-depen- 
dent contrast as a surrogate for neural activity. To date, published investigations using functional MR imaging to investigate depression have been performed on small numbers of patients.

George and colleagues ${ }^{45}$ reported relative hypoactivation of the ACC (but not in the subgenual area) during the Stroop test in depressed patients relative to healthy controls, and increased activity in the left dorsolateral prefrontal cortex. Subsequently, Kumari et al. ${ }^{67}$ reported reduced cerebral response in the rostral anterior cingulate during a cognitive affect processing task in patients with treatment-resistant depression. In another study, ${ }^{113}$ unmedicated depressed patients and control participants underwent functional MR imaging during performance of an emotional information processing task prior to initiating CBT. Patients whose pretreatment emotional reactivity was decreased in the subgenual cingulate cortex and high in the amygdala relative to healthy controls showed the most improvement with subsequent CBT. Abler and associates ${ }^{1}$ used functional MR imaging to study depressed and nondepressed patients who were instructed to anticipate and respond to positive, negative, and neutral images. The HRSD scores of depressed patients were found to correlate with activation of the left and right ventral amygdala during expectation of negative stimuli; that is, greater amygdala activation corresponded to a more severe depression.

\section{Magnetic Resonance Spectroscopy}

Magnetic resonance spectroscopy is used to detect differences in tissue concentrations of various neurochemicals by the analysis of spectral-specific peaks within a region of interest on MR imaging. A meta-analysis of $1 \mathrm{H}$ MR spectroscopy in major depressive disorder by Yildiz-Yesiloglu and Ankerst $^{131}$ noted that patients with major depression had levels of $\mathrm{N}$-acetylaspartate, a neuronal marker, that were similar to those of nondepressed healthy controls in the basal ganglia and frontal lobe regions of interest, suggesting normal neuronal numbers in major depression and contradicting the hypothesis that depression results in neuronal atrophy and loss. ${ }^{37}$ Choline, which is prevalent in oligodendrocytes, was noted to be elevated in the basal ganglia of patients with major depression, raising the possibility of an abnormality in glial function. ${ }^{37}$ The results of this meta-analysis thus support earlier studies that reported significantly lower glial cell numbers in postmortem studies of depressed patients but no alteration in neuronal number. ${ }^{37,93,102}$ A significant limitation of this meta-analysis, however, is the small number of studies that were included. More recently, Hasler and colleagues ${ }^{52}$ used MR spectroscopy at 3-T field strength to study brain metabolites in the prefrontal cortex and found that, relative to nondepressed healthy controls, unmedicated depressed patients had significantly reduced levels of glutamate/glutamine and (-aminobutyric acid in the dorsomedial, dorsoanterolateral, and ventromedial prefrontal areas, although autopsy findings have both supported ${ }^{37,93,131}$ and refuted ${ }^{51}$ this finding.

The temporal and spatial resolution needed to precisely define the altered activity within the functional networks that mediate depression may not be possible given current technology used for the study of human study participants. ${ }^{57}$ Nonetheless, taken together, the imaging findings presented above provide cross-modality support for the growing evidence implicating dysfunctional nodes within a complex network that mediates depression.

\section{Current Case Reports and Clinical Trials of DBS for Depression}

Psychotropic drugs, such as SSRIs, work by adjusting brain neurochemistry in widespread regions through the alteration of neurotransmitter levels at the synaptic cleft. The alteration in function of a specific neural network-if this is, in fact, the mechanism of action of DBS-would allow a more precise intervention and, therefore, the possibility of a more specific and effective therapy.

Information has been emerging from recent experience and ongoing trials of DBS for the treatment of OCD, Tourette syndrome, and treatment-refractory depression. From the ongoing trial of DBS for the treatment of OCD during active but not during sham programming, ${ }^{91}$ both improved and worsened mood responses have been noted from DBS in the anterior limb of the internal capsule/nucleus accumbens.

Depression can be viewed as a complicated network of interconnected white matter pathways and gray matter nodes, similar to OCD or Tourette syndrome. When viewed in this fashion, the finding that lesions or stimulation of various targets have been effective in ameliorating symptoms is not surprising. The question remains, however, as to which target constitutes the optimal site for DBS. Although the existing data do not yet answer this question, the results of recent case reports and clinical trials of DBS for the treatment of depression are described in greater detail below.

\section{Inferior Thalamic Peduncle DBS}

Noting that hypermetabolism has been documented in midline thalamic nuclei as well as in the OFC, ${ }^{32,126}$ Jiménez and colleague ${ }^{58}$ published a case report in which a patient with treatment-refractory major depression underwent implantation of bilateral DBS electrodes in the inferior thalamic peduncle, which connects the OFC with midline and intralaminar thalamic nuclei. Significant improvements were noted on the HRSD following insertion of the electrodes and during chronic stimulation. However, when stimulation was discontinued in a double-blind fashion, the patient's HRSD scores did not return to preoperative levels. Thus, it cannot be concluded that electrical stimulation of the inferior thalamic peduncle was responsible for the observed improvement in depression.

\section{Nucleus Accumbens DBS Trial}

Schlaepfer and colleagues ${ }^{109}$ chose to target the nucleus accumbens for the treatment of depression. Noting that anhedonia is a prominent feature of major depression, ${ }^{109,123}$ these investigators based their target selection on the following observations: 1) the nucleus accumbens-indeed the entire ventral striatum, of which the nucleus accumbens is a component-is involved in the processing of reward; 2) the ventral striatum, by virtue of its connections, is well located to control other portions of the putative limbic/affective loop; and 3) animal and human data support the hypothesis that the nucleus accumbens serves as a link between motor control systems and limbic control systems. 
Biological basis for the surgical treatment of depression

TABLE 1

Published studies of DBS for depression*

\begin{tabular}{|c|c|c|c|c|c|c|}
\hline Authors \& Year & Target & $\begin{array}{c}\text { Patient } \\
\text { Diagnosis }\end{array}$ & $\begin{array}{c}\text { DBS } \\
\text { (V) }\end{array}$ & $\begin{array}{l}\text { Respon- } \\
\text { ders/Total }\end{array}$ & Overall Response & Mean FU \\
\hline Schlaepfer et al., 2008 & nucleus accumbens & TRD & $3.5-5.0$ & $3 / 3$ & $38-83 \%$ decrease on 24 -item HRSD & $7 \mathrm{wks}$ \\
\hline Mayberg et al., 2005 & subgenual cingulate & TRD & 4.0 & $4 / 6$ & $\geq 50 \%$ decrease on 17 -item HRSD & $6 \mathrm{mos}$ \\
\hline Jimenez et al., 2005 & inferior thalamic peduncle & TRD & 2.5 & $1 / 1$ & $81 \%$ decrease on HRSD & $1-8 \mathrm{mos}$ \\
\hline Greenberg et al., 2006 & ventral capsule/ventral striatum & TRD & unknown & n $3 / 5$ & $\geq 50 \%$ decrease on 28 -item HRSD & 3 mos \\
\hline Aouizerate et al., 2004 & $\begin{array}{l}\text { ventral capsule/nucleus } \\
\text { accumbens }\end{array}$ & $\begin{array}{l}\text { OCD/ } \\
\text { MDD }\end{array}$ & 4.0 & $1 / 1$ & remission on 17-item HRSD & $15 \mathrm{mos}$ \\
\hline
\end{tabular}

* FU = follow-up; MDD = major depressive disorder; TRD = treatment-refractory depression.

Three patients with treatment-resistant depression, who had not responded to ECT, CBT, and adequate trials of more than 4 antidepressants and augmentation with multiple neuroleptics, underwent bilateral nucleus accumbens DBS implantation. Electrodes were turned on or off in a doubleblind fashion over the course of several months. Patients were not aware of the stimulation and experienced no adverse effects from stimulation. Using the 24-item HRSD and MADRS, the authors found acute stimulation-induced changes in motivation and documented significant improvements on HRSD and MADRS scores within 1 week of stimulation onset (Table 1). Sustained improvements in the HRSD scores of the 3 patients of 38,66 , and $83 \%$ were noted after a mean of 7 weeks of stimulation. Turning off stimulation in a double-blind manner resulted in a return toward prestimulation baseline HRSD and MADRS scores. The FDG-PET scans obtained after 1 week of DBS of the nucleus accumbens disclosed decreased metabolism in the ventromedial prefrontal cortex, ventrolateral prefrontal cortex (both areas noted to be hypermetabolic in depression), thalamus, and dorsal caudate nucleus, but increased metabolism in the ventral striatum/nucleus accumbens, dorsolateral prefrontal cortex, dorsomedial prefrontal cortex, amygdala, and cingulate cortex.

A different group of investigators used nucleus accumbens/ventral caudate DBS to treat a patient with OCD and comorbid major depression. ${ }^{4}$ The authors noted that this patient's depression did, in fact, respond to antidepressant medication prior to surgery. The patient's depression was therefore not treatment refractory. Nonetheless, within 6 months of stimulation at $4 \mathrm{~V}$, the patient's HRSD score dropped below 7 , meeting criteria for remission (Table 1).

\section{Brown University/Cleveland Clinic/University of Florida Depression Trial}

Greenberg and colleagues ${ }^{47}$ began studying the effects of DBS of the anterior limb of the internal capsule in 2001 for the treatment of medically refractory OCD. This target was chosen because of the historical results of anterior capsulotomy for the treatment of OCD. These investigators noticed consistent and early improvements in comorbid depressive symptoms. Over the course of the investigation, the target was modified to a more ventral location, in the underlying dorsal ventral striatum. This new target, the ventral capsule/ventral striatum, has now been used to treat 6 patients with treatment-refractory major depression. Interim results were published in 2004, with 5 of the 6 patients demonstrating improvements on the 28-item HRSD at 3 months of stimulation while patients and raters remained blinded to stimulation condition. Three of these patients demonstrated $>50 \%$ improvement on the HRSD at this time point. The authors noted that transient reversible hypomania, the most significant adverse event, ${ }^{47}$ became much less frequent with changes in stimulation technique. A Phase III multicenter clinical trial is currently underway to more fully explore the use of ventral capsule/ventral striatum DBS in the treatment of depression.

\section{Deep Brain Stimulation Study for Treatment-Resistant Depression}

Noting that the subgenual cingulate was involved in the mediation of acute induced sadness and implicated in the successful treatment of depression with antidepressants, Mayberg and colleagues ${ }^{80}$ focused their attention on this area in patients with treatment-refractory depression. Hypermetabolism in the subgenual cingulate was observed to normalize in patients with treatment-refractory depression successfully treated with SSRIs, but to persist in cases that were refractory to standard therapy. Recognizing that pathologically overactive circuits in PD normalize with clinically effective DBS of the basal ganglia, Mayberg and colleagues conducted a pilot study of DBS for treatmentrefractory depression. They hypothesized that the subgenual cingulate hypermetabolism in patients with treatmentrefractory depression would normalize with effective subgenual cingulate DBS and that remission of depression would be accompanied by normalization of subgenual cingulate activity on cerebral blood flow PET. Six patients underwent surgery for the implantation of bilateral subgenual cingulate DBS. All 6 patients met the Diagnostic and Statistical Manual of Mental Disorders (Fourth Edition, Text Revision) criteria for major depressive disorder; had a minimum score of 20 on the 17-item HRSD; and were identified as treatment-resistant after undergoing unsuccessful trials of a minimum of 4 different SSRIs, evidencebased psychotherapy, or ECT administered at adequate doses. Chronic bilateral subgenual cingulate DBS resulted in sustained remission on the HRSD in 4 of the 6 patients, with PET cerebral blood flow evidence of normalization of activity in the subgenual cingulate at 3 and 6 months of chronic stimulation (Fig. 2). None of the subjects experienced euphoria or symptoms of hypomania. Interestingly, blinded discontinuation of stimulation in 1 of the 4 responders resulted in a recurrence of behavioral symptoms such as loss of energy and initiative, impaired concentration, and reduced activity level, all of which returned to prior, pre- 


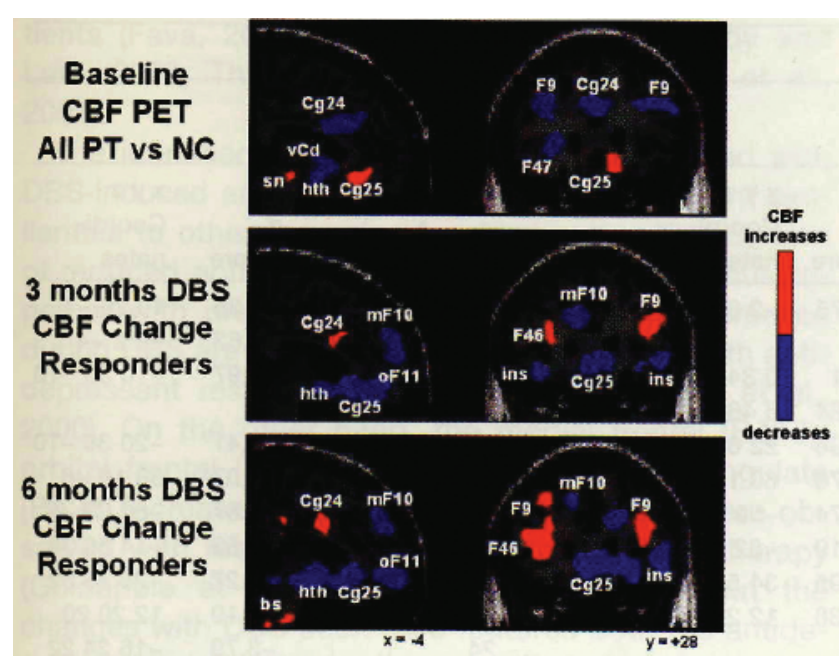

FIG. 2. Regional cerebral blood flow (CBF) changes on PET in patients (PT) with treatment-refractory depression at baseline, and after 3 and 6 months of successful treatment with continuous DBS of the subgenual cingulate $(\mathrm{Cg} 25)$. Baseline $\mathrm{CBF}$ abnormalities are depicted relative to age and sex-matched healthy controls (NC). Significant CBF increases are noted in red, and decreases in blue $(\mathrm{p}<0.001)$. Increases in $\mathrm{Cg} 25$ and decreases in dorsolateral prefrontal cortex (F9), ventrolateral prefrontal cortex (F47), and ACC $(\mathrm{Cg} 24)$ cortex $\mathrm{CBF}$ relative to healthy controls are noted at baseline. Decreases in $\mathrm{Cg} 25$, hypothalamus (Hth), anterior insula (ins), medial frontal $(\mathrm{mF} 10)$ and orbital frontal $(\mathrm{oF} 11)$ and increases in prefrontal (F9/F46) and F47 CBF are noted after 3 months of stimulation. This same pattern is maintained at 6 months, although additional increases are noted in the brainstem (bs). Numbers represent Brodmann area designations. $\mathrm{sn}=$ substantia nigra; $\mathrm{vCd}=$ ventral caudate nucleus. Reprinted from Mayberg HA, Lozano AM, Voon V, et al: Deep brain stimulation for treatment-resistant depression. Neuron 45:651-660, 2005, with permission from Elsevier.

discontinuation (baseline) levels with the blinded resumption of stimulation.

\section{Bonn/Cologne DBS Trial}

Schlaepfer and colleagues ${ }^{86,109}$ recently reported the results of DBS of the nucleus accumbens in 3 patients with treatment-refractory major depression. Noting that the nucleus accumbens plays an important role in the reward response and is interconnected with brain areas involved in the mediation of emotion-such as the subgenual cingulate, medial prefrontal cortex, and amygdala - these investigators targeted the nucleus accumbens in the hopes of modulating this emotional "network." Patients and raters were blinded to stimulation condition. Significant improvements in depression scores on the MADRS and 24-item HRSD were noted immediately in all 3 participants, with a return toward baseline depression scores when stimulation was discontinued in a blinded fashion. No side effects of stimulation could be detected by patients, and none were noted by investigators. Interestingly, given the role of the nucleus accumbens in motivation and reward, no significant change was noted in those items on the MADRS and HRSD, believed to assess anhedonia. A comparison of FDG-PET scans acquired 1 week prior to implantation and following 1 week of stimulation disclosed significant acti- vation bilaterally in the ventral striatum, including the nucleus accumbens, dorsomedial prefrontal cortex, and dorsolateral prefrontal cortex, as well as the cingulate cortex and amygdala. Deactivations were noted in ventromedial prefrontal cortex and ventrolateral prefrontal cortex (regions shown to be hypermetabolic in depression) and in the thalamus and dorsal caudate nucleus. No significant change in metabolic activity in the subgenual cingulate was found. It is important to note that these results represent only 1 week of follow-up.

\section{Animal Models of Depression}

Because the diagnosis of depression depends almost exclusively on observed behavior and interpersonal relations in conjunction with patient self-reports of feelings and beliefs, the development of an accurate animal model of human depression has thus far been elusive..$^{41}$ Animal models to date have included externally imposed stressors (such as restraints), social dominance models (such as rearing in isolation), and genetic susceptibility models (such as hypothalamic-pituitary-adrenal axis transgenes). Given that neurobiological, hormonal, cultural, and environmental factors all contribute in some fashion to the expression of depression, there is unlikely to be a single best animal model for the human condition of treatment-refractory depression, which is, itself, likely to be heterogeneous in terms of underlying pathophysiology. The reader is referred to Anisman and Matheson ${ }^{3}$ and Fuchs et al. $^{41}$ for excellent reviews of this topic. A fascinating study on the potential genetic underpinnings of depression was recently published by Berton et al. ${ }^{13}$

\section{Summary and Outlook}

Mounting evidence from the central nervous system injury literature, lesion surgery, functional imaging, and now DBS for treatment-refractory major depression supports the concept of depression as a network disorder rather than a perturbation in a single neurotransmitter or anatomical location in the brain. Functional imaging is providing a noninvasive means of beginning to elucidate the underlying mechanism of depression and responses to therapy.

There is substantial interest in exploring DBS for treatment-refractory depression. So as not to repeat the errors of the past, and to enable critical appraisals of future trials, it is essential to abide by certain fundamental guidelines for the conduct of clinical trials. These fundamental guidelines include the following: 1) establishment of rigorous inclusion and exclusion criteria for trials; 2) implementation of validated rating scales for pre- and postoperative assessments of disease severity; 3) using a multidisciplinary approach to study conduct, involving psychiatrists, neuropsychologists, neurologists, and neurosurgeons; 4) standardizing protocols across treating centers to facilitate comparisons of results; and 5) continued investigation into underlying mechanisms of depression and its response to interventions, so as to determine which therapies should be implemented and how these can be optimized for patients.

Further studies using DBS in combination with neuroimaging, as well as the development of better animal models for depression, should further our understanding of 
this disabling condition, as well as improve our ability to intervene therapeutically.

\section{References}

1. Abler B, Erk S, Herwig U, Walter H: Anticipation of aversive stimuli activates extended amygdala in unipolar depression. $\mathbf{J}$ Psychiatr Res 41:511-522, 2007

2. Alexander GE, DeLong MR, Strick PL: Parallel organization of functionally segregated circuits linking basal ganglia and cortex. Annu Rev Neurosci 9:357-381, 1986

3. Anisman H, Matheson K: Stress, depression, and anhedonia: caveats concerning animal models. Neurosci Biobehav Rev 29:525-546, 2005

4. Aouizerate B, Cuny E, Martin-Guehl C, Amieva H, Benazzouz A, Fabrigoule C, et al: Deep brain stimulation of the ventral caudate nucleus in the treatment of obsessive-compulsive disorder and major depression. Case report. J Neurosurg 101:682-686, 2004

5. Bae JN, MacFall JR, Krishnan KR, Payne ME, Steffens DC, Taylor WD: Dorsolateral prefrontal cortex and anterior cingulate cortex white matter alterations in late-life depression. Biol Psychiatry 60:1356-1363, 2006

6. Ballantine HT Jr, Bouckoms AJ, Thomas EK, Giriunas IE: Treatment of psychiatric illness by stereotactic cingulotomy. Biol Psychiatry 22:807-819, 1987

7. Ballmaier M, Toga AW, Blanton RE, Sowell ER, Lavretsky H, Peterson J, et al: Anterior cingulate, gyrus rectus, and orbitofrontal abnormalities in elderly depressed patients: an MRI-based parcellation of the prefrontal cortex. Am J Psychiatry 161:99-108, 2004

8. Barker-Collo SL: Depression and anxiety 3 months post stroke: prevalence and correlates. Arch Clin Neuropsychol 22:519-531, 2007

9. Baumann B, Danos P, Krell D, Diekmann S, Leschinger A, Stauch $\mathrm{R}$, et al: Reduced volume of limbic system-affiliated basal ganglia in mood disorders: preliminary data from a postmortem study. J Neuropsychiatry Clin Neurosci 11:71-78, 1999

10. Beblo T, Wallesch CW, Herrmann M: The crucial role of frontostriatal circuits for depressive disorders in the postacute stage after stroke. Neuropsychiatry Neuropsychol Behav Neurol 12:236246, 1999

11. Bejjani BP, Houeto JL, Hariz M, Yelnik J, Mesnage V, Bonnet AM, et al: Aggressive behavior induced by intraoperative stimulation in the triangle of Sano. Neurology 59:1425-1427, 2002

12. Berney A, Panisset M, Sadikot AF, Ptito A, Dagher A, Fraraccio $\mathrm{M}$, et al: Mood stability during acute stimulator challenge in Parkinson's disease patients under long-term treatment with subthalamic deep brain stimulation. Mov Disord 22:1093-1096, 2007

13. Berton O, McClung CA, Dileone RJ, Krishnan V, Renthal W, Russo SJ, et al: Essential role of BDNF in the mesolimbic dopamine pathway in social defeat stress. Science 311:864-868, 2006

14. Bingley T, Persson A: EEG studies on patients with chronic obsessive-compulsive neurosis before and after psychosurgery (stereotaxic bilateral anterior capsulotomy). Electroencephalogr Clin Neurophysiol 44:691-696, 1978

15. Botteron KN, Raichle ME, Drevets WC, Heath AC, Todd RD: Volumetric reduction in left subgenual prefrontal cortex in early onset depression. Biol Psychiatry 51:342-344, 2002

16. Bremner JD, Vythilingam M, Vermetten E, Nazeer A, Adil J, Khan S, et al: Reduced volume of orbitofrontal cortex in major depression. Biol Psychiatry 51:273-279, 2002

17. Brody AL, Saxena S, Silverman DH, Alborzian S, Fairbanks LA, Phelps ME, et al: Brain metabolic changes in major depressive disorder from pre- to post-treatment with paroxetine. Psychiatry Res 91:127-139, 1999

18. Brown P, Molliver ME: Dual serotonin (5-hT) projections to the nucleus accumbens core and shell: relation of the 5-hT transporter to amphetamine-induced neurotoxicity. J Neurosci 20:19521963,2000

19. Bush G, Luu P, Posner MI: Cognitive and emotional influences in anterior cingulate cortex. Trends Cogn Sci 4:215-222, 2000

20. Campbell S, MacQueen G: An update on regional brain volume differences associated with mood disorders. Curr Opin Psychiatry 19:25-33, 2006

21. Carson AJ, MacHale S, Allen K, Lawrie SM, Dennis M, House A, et al: Depression after stroke and lesion location: a systematic review. Lancet 356:122-126, 2000

22. Cosgrove GR, Rauch SL: Psychosurgery. Neurosurg Clin N Am 6:167-176, 1995

23. Cosgrove GR, Rauch SL: Stereotactic cingulotomy. Neurosurg Clin N Am 14:225-235, 2003

24. Deep Brain Stimulation for Parkinson's Disease Study Group: Deep-brain stimulation of the subthalamic nucleus or the pars interna of the globus pallidus in Parkinson's disease. N Engl J Med 345:956-963, 2001

25. DeLong MR, Wichmann T: Circuits and circuit disorders of the basal ganglia. Arch Neurol 64:20-24, 2007

26. Deuschl G, Schade-Brittinger C, Krack P, Volkmann J, Schäfer H, Bötzel K, et al: A randomized trial of deep-brain stimulation for Parkinson's disease. N Engl J Med 355:896-908, 2006

27. Devinsky O, Morrell MJ, Vogt BA: Contributions of anterior cingulate cortex to behavior. Brain 118:279-306, 1995

28. Dougherty DD, Baer L, Cosgrove GR, Cassem EH, Price BH, Nierenberg AA, et al: Prospective long-term follow-up of 44 patients who received cingulotomy for treatment-refractory obsessive-compulsive disorder. Am J Psychiatry 159:269275, 2002

29. Dougherty DD, Rauch SL: Somatic therapies for treatment-resistant depression: new neurotherapeutic interventions. Psychiatr Clin North Am 30:31-37, 2007

30. Dougherty DD, Weiss AP, Cosgrove GR, Alpert NM, Cassem EH, Nierenberg AA, et al: Cerebral metabolic correlates as potential predictors of response to anterior cingulotomy for treatment of major depression. J Neurosurg 99:1010-1017, 2003

31. Drapier D, Drapier S, Sauleau P, Haegelen C, Raoul S, Biseul I, et al: Does subthalamic nucleus stimulation induce apathy in Parkinson's disease? J Neurol 253:1083-1091, 2006

32. Drevets WC: Neuroimaging studies of mood disorders. Biol Psychiatry 48:813-829, 2000

33. Drevets WC: Orbitofrontal cortex function and structure in depression. Ann N Y Acad Sci 1121:499-527, 2007

34. Drevets WC, Bogers W, Raichle ME: Functional anatomical correlates of antidepressant drug treatment assessed using PET measures of regional glucose metabolism. Eur Neuropsychopharmacol 12:527-544, 2002

35. Drevets WC, Price JL, Simpson JR Jr, Todd RD, Reich T, Vannier $\mathrm{M}$, et al: Subgenual prefrontal cortex abnormalities in mood disorders. Nature 386:824-827, 1997

36. Drevets WC, Videen TO, Price JL, Preskorn SH, Carmichael ST, Raichle ME: A functional anatomical study of unipolar depression. J Neurosci 12:3628-3641, 1992

37. Duman RS, Malberg J, Nakagawa S, D'Sa C: Neuronal plasticity and survival in mood disorders. Biol Psychiatry 48:732-739, 2000

38. Foltz EL, White LE Jr: Pain "relief" by frontal cingulumotomy. J Neurosurg 19:89-100, 1962

39. Freedman LJ, Insel TR, Smith Y: Subcortical projections of area 25 (subgenual cortex) of the macaque monkey. J Comp Neurol 421:172-188, 2000

40. Friedman DP, Aggleton JP, Saunders RC: Comparison of hippocampal, amygdala, and perirhinal projections to the nucleus accumbens: combined anterograde and retrograde tracing study in the Macaque brain. J Comp Neurol 450:345-365, 2002

41. Fuchs E, Flugge G, Czeh B: Remodeling of neuronal networks by stress. Front Biosci 11:2746-2758, 2006

42. Funkiewiez A, Ardouin C, Caputo E, Krack P, Fraix V, Klinger H, 
et al: Long term effects of bilateral subthalamic nucleus stimulation on cognitive function, mood, and behavior in Parkinson's disease. J Neurol Neurosurg Psychiatry 75:834-839, 2004

43. Funkiewiez A, Ardouin C, Krack P, Fraix V, Van Blercom N, Xie $\mathrm{J}$, et al: Acute psychotropic effects of bilateral subthalamic nucleus stimulation and levodopa in Parkinson's disease. Mov Disord 18:524-530, 2003

44. Fure B, Wyller TB, Engedal K, Thommessen B: Emotional symptoms in acute ischemic stroke. Int J Geriatr Psychiatry 21: 382-387, 2006

45. George MS, Ketter TA, Parekh PI, Rosinsky N, Ring HA, Pazzaglia PJ, et al: Blunted left cingulate activation in mood disorder subjects during a response interference task (the Stroop). J Neuropsychiatry Clin Neurosci 9:55-63, 1997

46. Göktepe EO, Young LB, Bridges PK: A further review of the results of sterotactic subcaudate tractotomy. Br J Psychiatry 126:270-280, 1975

47. Greenberg BD, Malone DA, Friehs GM, Rezai AR, Kubu CS, Malloy PF, et al: Three-year outcomes in deep brain stimulation for highly resistant obsessive-compulsive disorder. Neuropsychopharmacology 31:2384-2393, 2006

48. Greenberg BD, Price LH, Rauch SL, Friehs G, Noren G, Malone $\mathrm{D}$, et al: Neurosurgery for intractable obsessive-compulsive disorder and depression: critical issues. Neurosurg Clin N Am 14: 199-212, 2003

49. Haber SN, Kim KS, Mailly P, Calzavara R: Reward-related cortical inputs define a large striatal region in primates that interface with associative cortical connections, providing a substrate for incentive-based learning. J Neurosci 26:8368-8376, 2006

50. Hamilton M: Development of a rating scale for primary depressive illness. Br J Soc Clin Psychol 6:278-296, 1967

51. Hashimoto K, Sawa A, Iyo M: Increased levels of glutamate in brains from patients with mood disorders. Biol Psychiatry 62: 1310-1316, 2007

52. Hasler G, van der Veen JW, Tumonis T, Meyers N, Shen J, Drevets WC: Reduced prefrontal glutamate/glutamine and gamma-aminobutyric acid levels in major depression determined using proton magnetic resonance spectroscopy. Arch Gen Psychiatry 64:193-200, 2007

53. Heimer L, Zahm DS, Churchill L, Kalivas PW, Wohltmann C: Specificity in the projection patterns of accumbal core and shell in the rat. Neuroscience 41:89-125, 1991

54. Hodgkiss AD, Malizia AL, Bartlett JR, Bridges PK: Outcome after the psychosurgical operation of stereotactic subcaudate tractotomy, 1979-1991. J Neuropsychiatry Clin Neurosci 7: 230-234, 1995

55. Houeto JL, Mallet L, Mesnage V, Tezenas du Montcel S, Béhar C, Gargiulo M, et al: Subthalamic stimulation in Parkinson disease: behavior and social adaptation. Arch Neurol 63:1090-1095, 2006

56. House A: Depression after stroke. Br Med J (Clin Res Ed) 294:76-78, 1987

57. Insel TR: Neuroscience. Shining light on depression. Science 317: 757-758, 2007

58. Jiménez F, Velasco F, Salin-Pascual R, Hernández JA, Velasco M, Criales JL, et al: A patient with a resistant major depression disorder treated with deep brain stimulation in the inferior thalamic peduncle. Neurosurgery 57:585-593, 2005

59. Johansen-Berg H, Gutman DA, Behrens TE, Matthews PM, Rushworth MF, Katz E, et al: Anatomical connectivity of the subgenual cingulate region targeted with deep brain stimulation for treatment-resistant depression. Cereb Cortex 18:1374-1383, 2007

60. Keller MB, Hirschfeld RM, Demyttenaere K, Baldwin DS: Optimizing outcomes in depression: focus on antidepressant compliance. Int Clin Psychopharmacol 17:265-271, 2002

61. Kelly D, Richardson A, Mitchell-Heggs N: Stereotactic limbic leucotomy: neurophysiological aspects and operative technique. Br J Psychiatry 123:133-140, 1973
62. Kennedy SH, Evans KR, Krüger S, Mayberg HS, Meyer JH, McCann S, et al: Changes in regional brain glucose metabolism measured with positron emission tomography after paroxetine treatment of major depression. Am J Psychiatry 158:899-905, 2001

63. Knight G: Stereotactic tractotomy in the surgical treatment of mental illness. J Neurol Neurosurg Psychiatry 28:304-310, 1965

64. Kosel M, Sturm V, Frick C, Lenartz D, Zeidler G, Brodesser D, et al: Mood improvement after deep brain stimulation of the internal globus pallidus for tardive dyskinesia in a patient suffering from major depression. J Psychiatr Res 41:801-803, 2007

65. Krack P, Kumar R, Ardouin C, Dowsey PL, McVicker JM, Benabid AL, et al: Mirthful laughter induced by subthalamic nucleus stimulation. Mov Disord 16:867-875, 2001

66. Kumar R, Krack P, Pollak P: Transient acute depression induced by high-frequency deep-brain stimulation. N Engl J Med 341: 1003-1004, 1999

67. Kumari V, Mitterschiffthaler MT, Teasdale JD, Malhi GS, Brown RG, Giampietro V, et al: Neural abnormalities during cognitive generation of affect in treatment-resistant depression. Biol Psychiatry 54:777-791, 2003

68. Kupsch A, Benecke R, Müller J, Trottenberg T, Schneider GH, Poewe $\mathrm{W}$, et al: Pallidal deep-brain stimulation in primary generalized or segmental dystonia. N Engl J Med 355:1978-1990, 2006

69. Lenze EJ, Sheline YI: Absence of striatal volume differences between depressed subjects with no comorbid medical illness and matched comparison subjects. Am J Psychiatry 156: 1989-1991, 1999

70. Li L, Ma N, Li Z, Tan L, Liu J, Gong G, et al: Prefrontal white matter abnormalities in young adult with major depressive disorder: a diffusion tensor imaging study. Brain Res 1168:124-128, 2007

71. Liotti M, Mayberg HS, McGinnis S, Brannan SL, Jerabek P: Unmasking disease-specific cerebral blood flow abnormalities: mood challenge in patients with remitted unipolar depression. Am J Psychiatry 159:1830-1840, 2002

72. Malhi GS, Bartlett JR: Depression: a role for neurosurgery? Br J Neurosurg 14:415-423, 2000

73. Mandat TS, Hurwitz T, Honey CR: Hypomania as an adverse effect of subthalamic nucleus stimulation: report of two cases. Acta Neurochir (Wien) 148:895-898, 2006

74. Mashour GA, Walker EE, Martuza RL: Psychosurgery: past, present, and future. Brain Res Brain Res Rev 48:409-419, 2005

75. Mayberg HS: Modulating dysfunctional limbic-cortical circuits in depression: towards development of brain-based algorithms for diagnosis and optimised treatment. Br Med Bull 65:193-207, 2003

76. Mayberg HS: Modulating limbic-cortical circuits in depression: targets of antidepressant treatments. Semin Clin Neuropsychiatry 7:255-268, 2002

77. Mayberg HS: Positron emission tomography imaging in depression: a neural systems perspective. Neuroimaging Clin $\mathbf{N}$ Am 13:805-815, 2003

78. Mayberg HS, Brannan SK, Mahurin RK, Jerabek PA, Brickman JS, Tekell JL, et al: Cingulate function in depression: a potential predictor of treatment response. Neuroreport 8:1057-1061, 1997

79. Mayberg HS, Brannan SK, Tekell JL, Silva JA, Mahurin RK, McGinnis S, et al: Regional metabolic effects of fluoxetine in major depression: serial changes and relationship to clinical response. Biol Psychiatry 48:830-843, 2000

80. Mayberg HS, Lozano AM, Voon V, McNeely HE, Seminowicz D, Hamani C, et al: Deep brain stimulation for treatment-resistant depression. Neuron 45:651-660, 2005

81. Meredith GE, Pattiselanno A, Groenewegen HJ, Haber SN: Shell and core in monkey and human nucleus accumbens identified with antibodies to calbindin-D28k. J Comp Neurol 365:628639, 1996 
82. Middleton FA, Strick PL: Basal ganglia and cerebellar loops: motor and cognitive circuits. Brain Res Brain Res Rev 31:236-250, 2000

83. Mindus P, Edman G, Andréewitch S: A prospective, long-term study of personality traits in patients with intractable obsessional illness treated by capsulotomy. Acta Psychiatr Scand 99:40-50, 1999

84. Mogenson GJ, Swanson LW, Wu M: Neural projections from nucleus accumbens to globus pallidus, substantia innominata, and lateral preoptic-lateral hypothalamic area: an anatomical and electrophysiological investigation in the rat. J Neurosci 3:189-202, 1983

85. Montoya A, Weiss AP, Price BH, Cassem EH, Dougherty DD, Nierenberg AA, et al: Magnetic resonance imaging-guided stereotactic limbic leukotomy for treatment of intractable psychiatric disease. Neurosurgery 50:1043-1052, 2002

86. Moro E, Poon YY, Lozano AM, Saint-Cyr JA, Lang AE: Subthalamic nucleus stimulation: improvements in outcome with reprogramming. Arch Neurol 63:1266-1272, 2006

87. Nemeroff CB, Mayberg HS, Krahl SE, McNamara J, Frazer A, Henry TR, et al: VNS therapy in treatment-resistant depression: clinical evidence and putative neurobiological mechanisms. Neuropsychopharmacology 31:1345-1355, 2006

88. Neumeister A, Wood S, Bonne O, Nugent AC, Luckenbaugh DA, Young T, et al: Reduced hippocampal volume in unmedicated, remitted patients with major depression versus control subjects. Biol Psychiatry 57:935-937, 2005

89. Nicola SM: The nucleus accumbens as part of a basal ganglia action selection circuit. Psychopharmacology 191:521-550, 2007

90. Nobuhara K, Okugawa G, Sugimoto T, Minami T, Tamagaki C, Takase K, et al: Frontal white matter anisotropy and symptom severity of late-life depression: a magnetic resonance diffusion tensor imaging study. J Neurol Neurosurg Psychiatry 77:120 122, 2006

91. Okun MS, Mann G, Foote KD, Shapira NA, Bowers D, Springer U, et al: Deep brain stimulation in the internal capsule and nucleus accumbens region: responses observed during active and sham programming. J Neurol Neurosurg Psychiatry 78:310-314, 2007

92. Ongür D, An X, Price JL: Prefrontal cortical projections to the hypothalamus in macaque monkeys. J Comp Neurol 401:480 505, 1998

93. Ongür D, Drevets WC, Price JL: Glial reduction in the subgenual prefrontal cortex in mood disorders. Proc Natl Acad Sci U S A 95:13290-13295, 1998

94. Osuch EA, Ketter TA, Kimbrell TA, George MS, Benson BE, Willis MW, et al: Regional cerebral metabolism associated with anxiety symptoms in affective disorder patients. Biol Psychiatry 48:1020-1023, 2000

95. Parent A, Carpenter MB: Carpenter's Human Neuroanatomy. Baltimore: Williams \& Wilkins, 1996

96. Penney JB Jr, Young AB: Speculations on the functional anatomy of basal ganglia disorders. Annu Rev Neurosci 6:73-94, 1983

97. Pillon B, Ardouin C, Dujardin K, Vittini P, Pelissolo A, Cottencin $\mathrm{O}$, et al: Preservation of cognitive function in dystonia treated by pallidal stimulation. Neurology 66:1556-1558, 2006

98. Pizzagalli D, Pascual-Marqui RD, Nitschke JB, Oakes TR, Larson $\mathrm{CL}$, Abercrombie HC, et al: Anterior cingulate activity as a predictor of degree of treatment response in major depression: evidence from brain electrical tomography analysis. Am J Psychiatry 158:405-415, 2001

99. Pontieri FE, Tanda G, Di Chiara G: Intravenous cocaine, morphine, and amphetamine preferentially increase extracellular dopamine in the "shell" as compared with the "core" of the rat nucleus accumbens. Proc Natl Acad Sci U S A 92:12304-12308, 1995

100. Postuma RB, Dagher A: Basal ganglia functional connectivity based on a meta-analysis of 126 positron emission tomography and functional magnetic resonance imaging publications. Cereb Cortex 16: 1508-1521, 2006

101. Poynton AM, Kartsounis LD, Bridges PK: A prospective clinical study of stereotactic subcaudate tractotomy. Psychol Med 25:763-770, 1995

102. Rajkowska G: Depression: what we can learn from postmortem studies. Neuroscientist 9:273-284, 2003

103. Rajkowska G, Miguel-Hidalgo JJ, Wei J, Dilley G, Pittman SD, Meltzer HY, et al: Morphometric evidence for neuronal and glial prefrontal cell pathology in major depression. Biol Psychiatry 45:1085-1098, 1999

104. Rauch SL: Neuroimaging and neurocircuitry models pertaining to the neurosurgical treatment of psychiatric disorders. Neurosurg Clin N Am 14:213-223, 2003

105. Ridout N, O’Carroll RE, Dritschel B, Christmas D, Eljamel M, Matthews K, et al: Emotion recognition from dynamic emotional displays following anterior cingulotomy and anterior capsulotomy for chronic depression. Neuropsychologia 45: 1735-1743, 2007

106. Robinson RG, Kubos KL, Starr LB, Rao K, Price TR: Mood disorders in stroke patients. Importance of location of lesion. Brain 107:81-93, 1984

107. Rogers MA, Kasai K, Koji M, Fukuda R, Iwanami A, Nakagome $\mathrm{K}$, et al: Executive and prefrontal dysfunction in unipolar depression: a review of neuropsychological and imaging evidence. Neurosci Res 50:1-11, 2004

108. Sax KW, Strakowski SM, Zimmerman ME, DelBello MP, Keck PE Jr, Hawkins JM: Frontosubcortical neuroanatomy and the continuous performance test in mania. Am J Psychiatry 156:139-141, 1999

109. Schlaepfer TE, Cohen MX, Frick C, Kosel M, Brodesser D, Axmacher N, et al: Deep brain stimulation to reward circuitry alleviates anhedonia in refractory major depression. Neuropsychopharmacology 33:368-377, 2008

110. Schüpbach WM, Chastan N, Welter ML, Houeto JL, Mesnage V, Bonnet AM, et al: Stimulation of the subthalamic nucleus in Parkinson's disease: a 5 year follow up. J Neurol Neurosurg Psychiatry 76:1640-1644, 2005

111. Schuurman PR, Bosch DA, Bossuyt PM, Bonsel GJ, van Someren EJ, de Bie RM, et al: A comparison of continuous thalamic stimulation and thalamotomy for suppression of severe tremor. N Engl J Med 342:461-468, 2000

112. Sheline YI: Neuroimaging studies of mood disorder effects on the brain. Biol Psychiatry 54:338-352, 2003

113. Siegle GJ, Carter CS, Thase ME: Use of FMRI to predict recovery from unipolar depression with cognitive behavior therapy. Am J Psychiatry 163:735-738, 2006

114. Snaith RP, Ahmed SN, Mehta S, Hamilton M: Assessment of the severity of primary depressive illness. Wakefield self-assessment depression inventory. Psychol Med 1:143-149, 1971

115. Spangler WJ, Cosgrove GR, Ballantine HT Jr, Cassem EH, Rauch SL, Nierenberg A, et al: Magnetic resonance imageguided stereotactic cingulotomy for intractable psychiatric disease. Neurosurgery 38:1071-1078, 1996

116. Starkstein SE, Robinson RG, Berthier ML, Parikh RM, Price TR: Differential mood changes following basal ganglia vs thalamic lesions. Arch Neurol 45:725-730, 1988

117. Starkstein SE, Robinson RG, Price TR: Comparison of cortical and subcortical lesions in the production of poststroke mood disorders. Brain 110:1045-1059, 1987

118. Steele JD, Christmas D, Eljamel MS, Matthews K: Anterior cingulotomy for major depression: clinical outcome and relationship to lesion characteristics. Biol Psychiatry 63:670677, 2007

119. Stockmeier CA, Mahajan GJ, Konick LC, Overholser JC, Jurjus GJ, Meltzer HY, et al: Cellular changes in the postmortem hippocampus in major depression. Biol Psychiatry 56:640 650,2004

120. Ström-Olsen R, Carlisle S: Bi-frontal stereotactic tractotomy. A 


\section{A. Abosch and G. R. Cosgrove}

follow-up study of its effects on 210 patients. Br J Psychiatry 118:141-154, 1971

121. Taylor WD, MacFall JR, Payne ME, McQuoid DR, Provenzale JM, Steffens DC, et al: Late-life depression and microstructural abnormalities in dorsolateral prefrontal cortex white matter. Am J Psychiatry 161:1293-1296, 2004

122. Temel Y, Kessels A, Tan S, Topdag A, Boon P, Visser-Vandewalle V: Behavioural changes after bilateral subthalamic stimulation in advanced Parkinson disease: a systematic review. Parkinsonism Relat Disord 12:265-272, 2006

123. Tremblay LK, Naranjo CA, Graham SJ, Herrmann N, Mayberg HS, Hevenor S, et al: Functional neuroanatomical substrates of altered reward processing in major depressive disorder revealed by a dopaminergic probe. Arch Gen Psychiatry 62: 1228-1236, 2005

124. Utter AA, Basso MA: The basal ganglia: an overview of circuits and function. Neurosci Biobehav Rev 32:333-342, 2007

125. Vakili K, Pillay SS, Lafer B, Fava M, Renshaw PF, BonelloCintron CM, et al: Hippocampal volume in primary unipolar major depression: a magnetic resonance imaging study. Biol Psychiatry 47:1087-1090, 2000

126. Velasco F, Velasco M, Jiménez F, Velasco AL, Salin-Pascual R: Neurobiological background for performing surgical intervention in the inferior thalamic peduncle for treatment of major depression disorders. Neurosurgery 57:439-448, 2005
127. Vidailhet M, Vercueil L, Houeto JL, Krystkowiak P, Benabid AL, Cornu P, et al: Bilateral deep-brain stimulation of the globus pallidus in primary generalized dystonia. N Engl J Med 352:459-467, 2005

128. Videbech P: PET measurements of brain glucose metabolism and blood flow in major depressive disorder: a critical review. Acta Psychiatr Scand 101:11-20, 2000

129. Whyte EM, Mulsant BH, Vanderbilt J, Dodge HH, Ganguli M: Depression after stroke: a prospective epidemiological study. J Am Geriatr Soc 52:774-778, 2004

130. Woerdeman PA, Willems PW, Noordmans HJ, Berkelbach van der Sprenkel JW, van Rijen PC: Frameless stereotactic subcaudate tractotomy for intractable obsessive-compulsive disorder. Acta Neurochir (Wien) 148:633-637, 2006

131. Yildiz-Yesiloglu A, Ankerst DP: Review of $1 \mathrm{H}$ magnetic resonance spectroscopy findings in major depressive disorder: a meta-analysis. Psychiatry Res 147:1-25, 2006

Manuscript submitted March 24, 2008.

Accepted April 15, 2008.

Sources of support: none reported.

Address correspondence to: Aviva Abosch, M.D., Ph.D., Department of Neurosurgery, University of Minnesota Medical School, D429 Mayo Memorial Building, 420 Delaware Street SE, MMC 96, Minneapolis, MN 55455. email: aabosch@umn.edu. 